\title{
Tobacco Related Habits vs Oral Mucosa
}

\author{
Shyam ${ }^{1}$, Sravya $\mathrm{T}^{2}$, Rajani $\mathrm{K}^{3}$
}

Praveen Kumar Manchikatla ${ }^{4}$

\section{Quick Response Code}

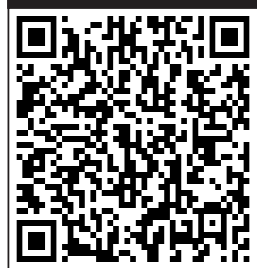

doi: $10.5866 / 2015.7 .10192$

1Post Graduate

2\&3Senior Lecturer

${ }^{4}$ Professor

Department of Oral Pathology,

Mamata Dental College, Khammam, Telangana

\section{Article Info:}

Received: J uly 12, 2015

Review Completed: August 11, 2015

Accepted: September 10, 2015

Available Online: J uly, 2015 (www.nacd.in)

C NAD, 2015 - All rights reserved

\section{E mail for correspondence:}

saibds95@gmail.com

\section{INTRODUCTION:}

The word tobacco was initially used to denote a Y - shaped piece of cone or pipe called Tobago or toba caused by Mexican I ndians to inhale powdered leaves of a plant. Later the plant came to be known by the name of the device, as "tobacco". ${ }^{1}$ The nicotine found in substantial amounts in tobacco products is widely considered to be a powerful addicting drug, so much so that its addictive processes and potential have been equated with heroine, morphine and cocaine. Its rapid absorption through the lungs of cigarette smokers is widely accepted, but it's equally ready absorption through the oral mucosa under the alkaline conditions is less publicized.

Among 400 million individuals aged 15yrs and over in India, $47 \%$ use tobacco in one form or the other. Some $72 \%$ of tobacco users smoke bidis, $12 \%$

\begin{abstract}
:
Various oral mucosal lesions are attributed to tobacco use. The presence of these conditions varies with particular type of tobacco used (smoking or smokeless) and the form in which it is used, such as cigarettes, pipes, cigars and chewing moist snuff. The frequency and duration as well as the ways in which the tobacco product is used also contribute to the clinical presentation and severity of the lesion. The systemic effects of tobacco have been extensively explored and reported, but the local oral effects of various tobacco habits have received little attention. The purpose of this article is to summarize current concepts of such local effects, especially the potentially malignant changes in the mouth.
\end{abstract}

Key words: tobacco, oral mucosa, nicotine, oral lesions, potentially malignant.

smoke cigarettes, 16\% use smokel ess tobacco. Of 250 million kg tobacco cleared for domestic consumption in India, $86 \%$ is used for smoking and $14 \%$ in smokeless form. ${ }^{1}$ Tobacco is used in a variety of forms, mostly as smoked, but many populations use smokeless tobacco, which comes in two main forms; snuff (finely ground or cut tobacco leaves that can be dry or moist, loose or portion packed in sachets) and chewing tobacco (loose leaf, inpouches of tobacco leaves, plug or twist form). ${ }^{2}$

\section{Harmful substances in tobacco:}

Smoked and smokeless tobacco contains nicotine as an important constituent. Thousands of chemical compounds in tobacco act not only as irritants and toxins but carcinogens. Over 300 carcinogens have been identified in tobacco smoke or in its water soluble components which can be 
expected to leach into saliva. The important carcinogens are listed below:

- aromatic hydrocarbons,

- benzopyrene and tobacco specific nitrosamines,

- N-nitrosononicotine (NNN),

- nitrosopyrollidine (NYPR),

- nitrosodimethylamine (NDMA) and

- 4-(methyl nitrosamine)-1-(3-pyridyl)-1butanone(NNK).

Benzopyrene is a powerful carcinogen which accounts to about 20-40mg per cigarette. The main stream smoke of a cigarette contains $310 \mathrm{mg}$ of NNN and 150ng of NNK. These agents act locally on keratinocytes, stem cells and are absorbed and act in many other tissues in the body. ${ }^{3}$

\section{Tobacco Related Habits (Table 1):}

Smoked and smokeless tobacco forms are used in different fashions referred to as habits (Figure 1). ${ }^{1}$

\section{Oral mucosal response:}

Tobacco consumption is positively correlated with accumulation of DNA damage. Exposure to tobacco-related chemical carcinogens could provide direct damaging effects on the cellular DNA in the human oral cavity. Tobacco constituents effects the oral mucosa in different ways finally leading to cancer through carcinogenesis. ${ }^{4}$

Tobacco products act as chemical carcinogens and participate in chemical carcinogenesis. First, the initiating carcinogens in tobacco which act as reactive electrophiles (having electron deficient atoms) react with nucleophilic (electron rich) sites in the cell. Their targets are DNA, RNA and proteins and in some cases may cause cell death. I nitiation inflicts nonlethal damage on the DNA that cannot be repaired. The mutated cell then passes on the DNA lesions to its daughter cells. ${ }^{4}$ I nitiating carcinogens are generally of two types. They are direct and indirect acting agents. ${ }^{5}$

Tobacco constituents are mainly indirect acting agents. There are some metabolic pathways which lead to inactivation of procarcinogen or its derivatives. Thus the carcinogenic potency of a chemical is determined not only by the inherent reactivity of its electrophilic derivative but also by the balance between metabolic activation and inactivation reactions. ${ }^{5}$ (Table 2 )

Benzopyrene, the primary constituent of tobacco is metabolized by the product of P-450 gene, CYP1A1. Light smokers with the susceptible genotype CYP1A1 have a sevenfold higher risk of devel oping lung cancer, compared with smokers without the susceptible genotype. So, variations in the activation or detoxification of carcinogens play an important role in the causation of cancer by tobacco products. ${ }^{6}$

Polycyclic aromatic hydrocarbons and benzopyreneare mutagenic and results in malignant transformation of a lesion. Their primary target is DNA and the important genes include commonly mutated oncogenes and tumour suppressors such as RAS and p53. ${ }^{4}$

When oral mucosa is continuously affected by tobacco carcinogens, unrepaired alterations in the DNA of mucosal epithelial cells occur which is the first step in the process of initiation. Inorder to inherit the change, the damaged DNA template must be replicated. Thus, carcinogen-altered cells must undergo atleast one proliferation cycle to fix the change in DNA., 3

Initiation is followed by promotion and promoters are the agents which donot cause mutation but stimulatethe division of mutated cells. Nicotine and phenols in tobacco act as promoters which are nontumorigenic by themselves, but augment the carcinogenicity of benzopyrene and polycyclic aromatic hydrocarbons (initiators). Promotion includes multiple steps such as proliferation of preneoplastic cells, malignant conversion, and eventually tumour progression which finally results in oral cancer. ${ }^{6}$

Tobacco, during the process of carcinogenesis attack the oral mucosa and results in various diseases and lesions depending on the type of tobacco product used, type of habit and duration of exposure. The lesions included are listed in Table 3.

\section{Leukoplakia}

In 1978, WHO defined leukoplakia as a white patch or plaque that cannot be characterized clinically or pathologically as any other disease. ${ }^{7}$ Later in 1984 at International seminar at Malmo, leukoplakia was defined as "A white patch or plaque that cannot be characterized clinically or 
pathologically as any other disease and which is not associated with any physical or chemical agent except the use of tobacco. ${ }^{8}$ The clinical types of leukoplakia are (1) homogeneous (2) ulcerated (3) ulcerated with pigmentation (3) nodular (4) speckled and (5) verruciform. ${ }^{1}$

Smokeless tobacco induced lesion is found to be more prevalent than leukoplakia mainly because the habit of taking smokeless tobacco is more common compared to smoking. Even it requires Ionger exposure with smoke to develop leukoplakia than smokeless tobacco induced lesion as it develops rapidly due to continuous local irritation by the placement of betel quid. ${ }^{9}$ Leukoplakia is always associated with smoking habits only and it was proved by many studies. ${ }^{10}$ Among all the smoking habits, bidi smoking was found to be most prevalent in Indian population. ${ }^{1}$

Leukoplakias associated with a smoking habit have a better prognosis compared to those not associated with a smoking habit as after smoking cessation, most of the smoking-related leukoplakias will disappear. ${ }^{11}$ Clinically, smoking induced leukoplakias are characterised by fine white striae that imitate a fingerprint pattern in the mucosa. So, the lesions are referred to as fingerprint lesions or a pumice stone type of Iesion which possibly disappear upon tobacco cessation and are generally consider ed as non-premalignant. ${ }^{12}$ There is a site and tobacco habit relationship in leukoplakia (Figure 2). ${ }^{1}$

Leukoplakia on buccal mucosa: It is seen in individuals who smoke until only the small "butt" of cigarette remains.

Hookli associated leukoplakia: The stem of hookli becomes hot when smoked causing leukoplakic lesions on lower and upper labial mucosa. These lesions usually have a delicate keratinized appearance.

Mishri associated leukoplakia: Mishri is a roasted powdered tobacco popularly used for application over teeth and gingiva. These lesions occur most often on labial mucosa and gingiva. The associated lesions are thick and extensive, faint and small.

Homogeneous leukoplakia on labial commissure: It is most common in beedi smokers

Ulcerated leuoplakia: It is most common in commissure areas.
Khaini associated leukoplakia: These lesions are usually thin and white with cracked mud appearance occurring most commonly in premolar region of the buccal mucosa. Nodular leukoplakia shows higher risk for malignant transformation. ${ }^{1}$

In leukoplakias, the histopathological manifestations were mainly in the form of hyperparakeratinization and hyperorthokeratinization independent of their clinical variants excluding verrucous leukoplakia which presents predominantly with hyperparakeratinization with parakeratin plugging. Other features include acanthosis and various grades of dysplasia. ${ }^{7}$

\section{Palatal changes in reverse smokers}

Reverse smoking evokes diversealterations in the palatal mucosa which can be of various patterns such as palatal keratosis, excrescences, patches, red areas, ulcerations and pigmentation changes (Figure 3 ). ${ }^{1}$

(1) Palatal keratosis presents as diffuse whitening of palatal mucosa. (2) Excrescences are 1-3 mm elevated reas, with central red dots representing the orifices of palatal minor salivary glands. (3) Patches are well defined, elevated plaques. (4) Red areas are well defined reddening of palatal mucosa. (5) Ulcerated areas are crater like ulcerations with deposits of fibrin surrounded by keratinization. (6) Hyperpigmentation is a protective reaction to heat and smoke from tobacco. (7) Nonpigmented areas denote areas devoid of melanin pigmentation. Loss of pigmentation renders oral mucosa more vulnerable to action of carcinogens in tobacco. ${ }^{1}$

\section{Snuff dippers lesions}

According to Hirsch et al, in snuff users there will be higher incidence of keratinized lesions, sialadenitis and slight dysplasia. ${ }^{2}$ The oral mucosa reacts to snuff by inducing hyperplasia in the basal cell layers and lethal damage in the surface layers. J uxta-epithelial band of sulphated mucopolysaccharides (GAGs) is usually seen as a stromal reaction to external damage by the snuff. The salivary glands and excretory ducts exhibits degenerative changes. Sialadenitis is more common compared to pathological changes in mucosal epithelium. The loss of salivary gland functions leads to a decreased production of saliva and hence decreased protection of the epithelium against snuff and other exogenous factors. ${ }^{2}$ 

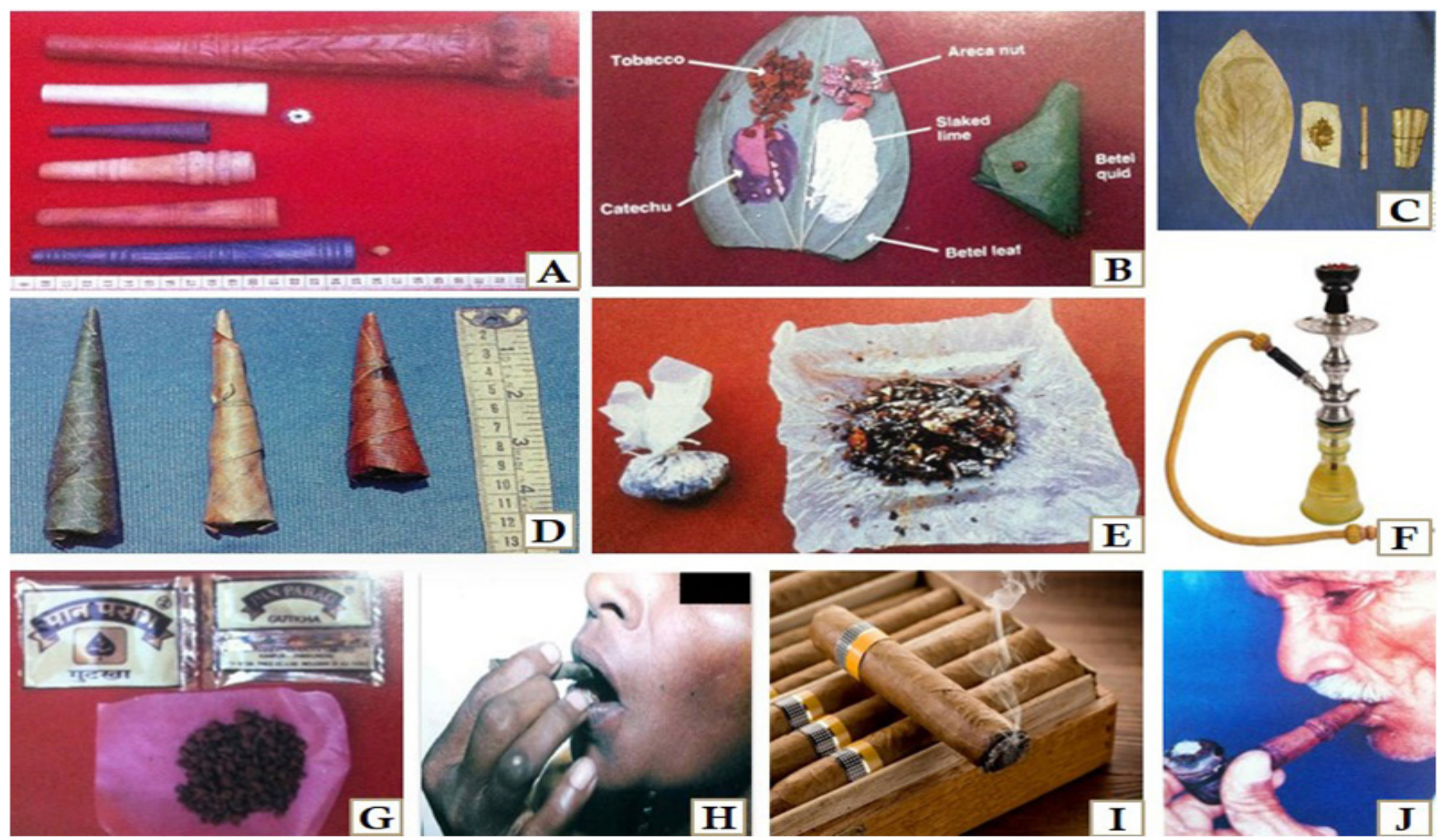

Figure 1: Tobacco related habits (A) Chilums (B) Betel quid (C)Beedi (D) Dhumti(E) Mawa preparation(F) Hookah(G) Pan masala containing tobacco $(\mathrm{H})$ Reverse smoking (I) Cigar (J) Hookli smoker (From Fali S. Mehta, Hamner J E. Tobacco related oral mucosal lesions and conditions in India. A guide for dental students, dentists and physicians. Basic dental research unit. Tata institute of fundamental research.1993, Bombay.)
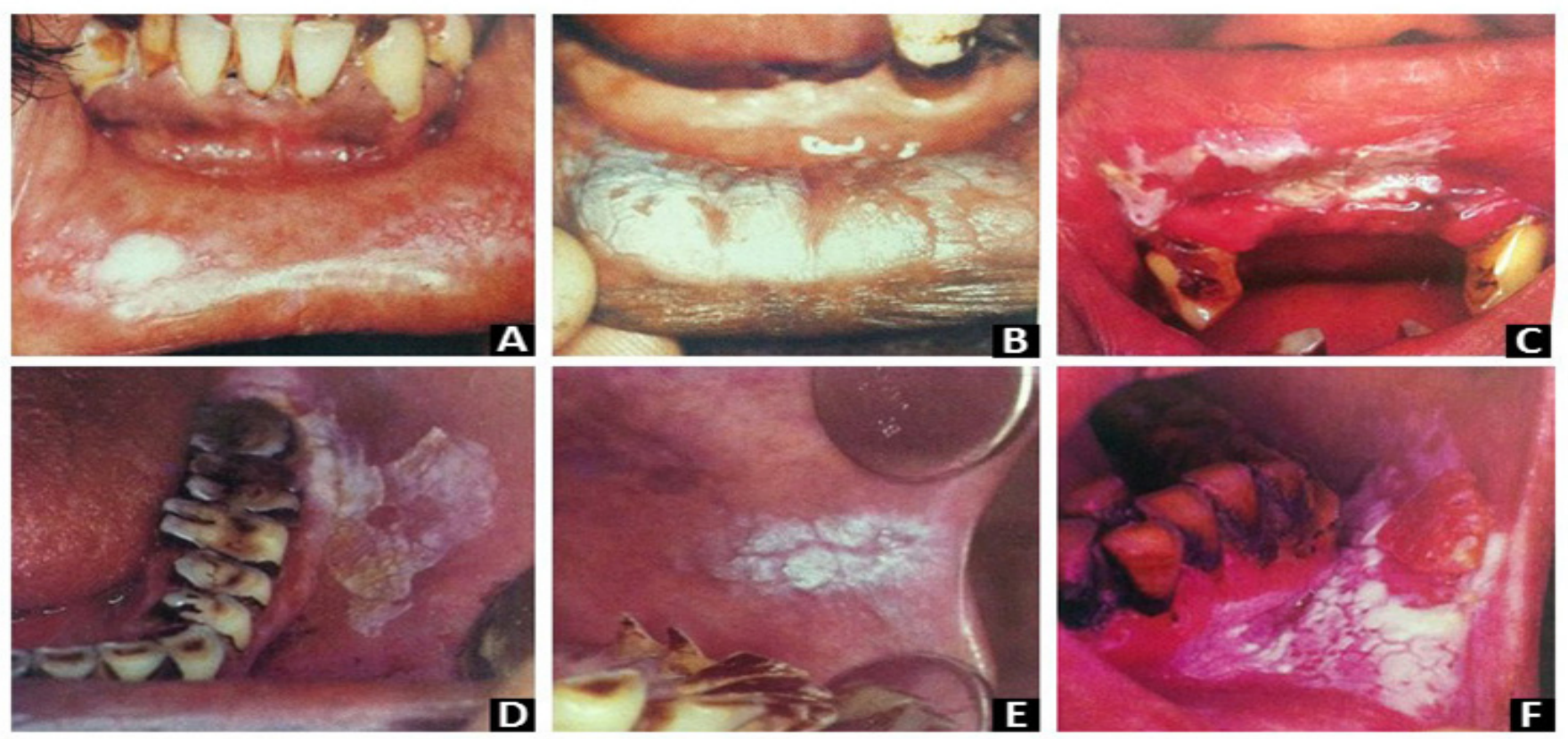

Figure 2: Leukoplakia: clinical types based on tobacco related habit (A) Lesion in individuals smoked till last 'butt' remains (B) homogeneous leukoplakia-delicate white keratinized pattern in a hookli smoker (C) Thick homogeneous leukoplakia - mishri use (D) Leukoplakia - betel quid chewer (E) Homogeneous leukoplakia cracked mud appearance - beedi smoker (F) Homogeneous leukoplakia - khaini user. (From Fali S. Mehta, Hamner J E. Tobacco related oral mucosal lesions and conditions in India. A guide for dental students, dentists and physicians. Basic dental research unit. Tata institute of fundamental research.1993, Bombay.) 

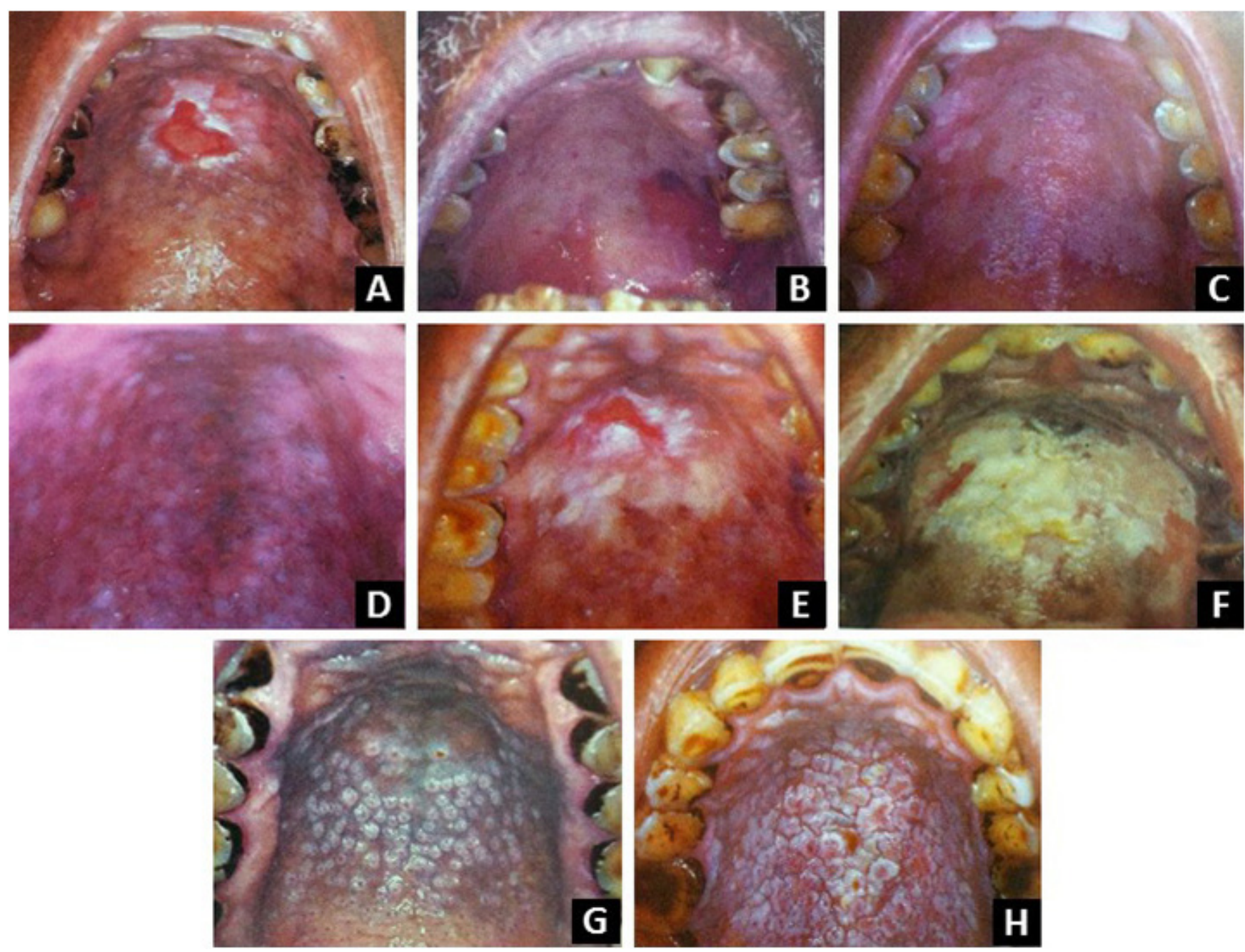

Figure 3: Palatal changes in reverse smokers (A) Ulceration with peripheral keratinization (B) red areas (C) palatal keratosis $(D)$ pigmentation $(E)$ non pigmented area $(F)$ palatal patch $(G)$ excrescences $(E)$ multimorphic palatal lesion showing excrescences and patches with fissuring. (From Fali S. Mehta, Hamner J E. Tobacco related oral mucosal lesions and conditions in India. A guide for dental students, dentists and physicians. Basic dental research unit. Tata institute of fundamental research.1993, Bombay.)

\section{Table 1: Tobacco related habits}

\section{SMOKING HABITS}

- $\quad$ Cigarette

- Bidi

- Cigar/cheroot/chutta

- Reverse chutta smoking

- Dhumti

- Reverse dhumti smoking

- Hookli smoking

- Chilum

- hookah

\section{SMOKELESS TOBACCO USE}

- $\quad$ Pan(betel quid) with tobacco

- Pan masala

- Mainpuri tobacco

- Mawa

- Tobacco-lime preparation 
Table 2: Harmful effects of tobacco constituents

\begin{tabular}{ll} 
Substance & Effect \\
Tar & Carcinogenesis \\
\hline Polycyclic aromatic hydrocarbons & Carcinogenesis \\
\hline Nicotine & Ganglionic stimulation and depression; tumour promotion \\
\hline Phenol & Tumour promotion; mucosal irritation \\
\hline Benzopyrene & Carcinogenesis \\
\hline Carbon monoxide & Impaired oxygen transport and utilization \\
\hline Formaldehyde & Toxicity to cilia; mucosal irritation \\
\hline Oxides of nitrogen & Toxicity to cilia; mucosal irritation \\
\hline Nitrosamine & Carcinogenesis \\
\hline
\end{tabular}

Table 3: Tobacco induced lesions

\begin{tabular}{|c|c|c|}
\hline Smoking & Chewing & Smoking and chewing \\
\hline 1. Leukoplakia & 1. Paan chewers lesion & Leukoplakia \\
\hline 2. Leukokeratosis nicotiana palate & Oral lichenplanus like lesion & Oral lichen planus \\
\hline 3. Palatal erythema & 3. Oral submucous fibrosis & Oral squamous cell \\
\hline
\end{tabular}

Smokel ess tobacco contains high concentrations of calcium, which promotes epithelial differentiation; perhaps the calcium levels in the oral cavity leads to the keratinization of normally nonkeratinized mucosa. Theincreased keratin thickness may be due to increased keratinocyte proliferation, decreased cell shedding in the keratin layer or both. ${ }^{13}$ Murrah et al demonstrated that tobacco components are capable of stimulating this proliferation. ${ }^{14}$

\section{Nicotinic stomatitis}

Also called smokers palate as it most commonly occurs on the palatal mucosa. It was named as stomatitis nicotina by Thoma in the year 194las the lesion is frequently reported in tobacco smokers. ${ }^{15}$ Pipe smokers and the individuals with reverse smoking habit develop this lesion most often compared to cigarette and cigar smokers. ${ }^{16}$ Depending on the smoking habit and duration, the heat released attacks the palatal mucosa and minor salivary glands and produce the characteristic clinical picture. Hard palate turns gray to white coloured depending on the amount of smoke. Scattered raised areas are ususally present with red coloured centers. Raised areas are formed by the clumps of minor salivary glands and their duct openings are seen as red dots because they donot keratinize instead the entire palate undergo keratinization and appears white. ${ }^{17}$ It does not transform into malignancy as it is a response to the heat of tobacco smoke rather than the chemicals. It is completely reversible within a few months of quitting the smoking habit. ${ }^{16}$

\section{Oral Submucous Fibrosis:}

Oral submucous fibrosis (OSMF) is a chronic, potentially malignant disorder of oral mucosa which was first described by Scwartz in $1952 .{ }^{18}$ The major effect of this disease lies in its inability to open the mouth and possessing the highest malignant transformation rate which accounts to about $7-13 \% .{ }^{19}$ The Etiopathogenesis of OSMF is much more complex and involves multiple factors such as consumption of chillies, nutritional deficiencies, betel quid chewing, genetic susceptibility, altered salivary constituents, autoimmunity and collagen disorders. ${ }^{20}$ Above all, betel quid chewing with or without tobacco constitutes a major risk factor.$^{21} \mathrm{All}$ the betel quid components have their individual effects on oral mucosa either directly or indirectly. Areca nut is the important and main ingredient which affects the oral mucosa. Areca nut contains areca alkaloids such as arecaidine, guvacoline, guvacaine. Among which arecoline is the main causative agent which is responsible for fibroblast proliferation. In the presence of slaked lime 
$\left(\mathrm{Ca}(\mathrm{OH})_{2}\right)$, arecoline hydrolyzes to arecai dine which stimulate fibroblasts and causes el evated collagen synthesis. Areca flavonoids such as tannins and catechins cause increased fibrosis by forming more stable and non-soluble collagen structure by inhibiting collagenase enzyme activity. Studies showed that there is 1.5 fold increase in collagen production by OSMF fibroblasts and as the disease progressed type III collagen is completely replaced by type $\mathrm{I}^{22}$

In a normal tissue, collagen is degraded by phagocytosis whereas in OSMF, arecoline suppresses $T$ cell activity which in turn decreases the cell mediated immunity resulting in decreased phagocytosis. ${ }^{23}$

Copper present in the areca nut causes upregulation of Iysyl oxidase enzyme which increases crosslinking of collagen and elastin molecules. The enzyme levels increases during fibrogenesis in OSMF . ${ }^{24}$ Areca nut acts as an external stimuli and induce OSM $F$ by increasing the levels of cytokines in the lamina propria and also the production of cytokines by peripheral mononuclear cells. Theliterature shows that OSMF susceptibility could be cytokine based i.e., they increase the genetic susceptibility of OSMF patients resulting in more penetration of arecoline and arecaidine into the oral mucosa. ${ }^{25}$

Lime which is a major component of betel quid causes change in oral cavity environment from neutral toalkaline. Under alkaline conditions, areca nut ingredients release reactive oxygen species (ROS). At ph $>9.5$ areca phenols (tannins and catechins) undergo auto oxidation to release superoxide radicals and $\mathrm{H}_{2} \mathrm{O}_{2}$. These ROS then reacts with DNA and causes modification of nucleotide by forming 8-hydroxydeoxygaunosine which leads to the formation of mutated initiated cells during replication. This finally leads to malignant transformation of OSMF.26, 27

\section{Smokers Melanosis}

Smoker's melanosis is a brownish discoloration of the oral mucosa. Cigarette smokers usually present lesions on the mandibular anterior gingiva whereas the pipe smokers on the buccal mucosa. Reverse smokers (people who place the lit end of a cigarette into the oral cavity) present normally the pigmentation of hard palate. Smoker's melanosis increases with age which suggests that the longer the person smokes, the more likely he will develop the condition. Nicotine (a polycyclic compound) is an important constituent of tobacco smoke which may be the main cause of smokers melanosis. Nicotine acts on melanocytes located al ong the basal cell layer of thelining epithelium of the oral mucosa and directly stimulate them to produce more melanosomes. This results in increased deposition of melanin pigment as basilar melanosis with varying amounts of melanin incontinence. ${ }^{28}$ Anders Hedin conducted study to evaluate frequency and extension of melanin pigmentation in the attached gingiva and its relation to tobacco smoking. He concluded that smoker's melanosis is considered to be caused by tobacco smoking and is expected to be found in other parts of oral mucosa. ${ }^{29}$

\section{Oral cancer:}

The highest relative risk for cancer due to smoking is the lung followed by larynx and oral cavity. ${ }^{30}$ The risk of oral cancer has increased in recent decades in many countries in the world. Several studies evidenced that oral cancers are the result of mutagenic events (arising mainly from tobacco and alcohol) causing multiple molecular genetic events in many chromosomes and genes. The effect of this chromosomal (genetic) damage is the impairment of cell regulatory processes which lead to acquired capabilities within cells such as selfsufficiency in growth signals, insensitivity to antigrowth signals, evading apoptosis, limitless replicative potential, sustained angiogenesis and tissue invasion and metastasis. ${ }^{31}$

As already discussed, Two main carcinogens present in tobacco smoke are benzo(a) pyrine and tobacco smoke derived nitrosamines (TSNA). These are primarily metabolised to their activated molecules by cytochrome P450 andthese intermediates are detoxified by glutathione Stransferase (GST) to hydrophilic and non-toxic GST conjugated substances. ${ }^{32}$ Genetic polymorphisms in these metabolising enzyme systems (Cytochrome P450 and GST) and the resulting variants explain the susceptibility to cancer in various organs. If detoxification fails, then the metabolically activated tobacco products would adduct to DNA and form DNA adducts. The DNA adducts associated with tobacco smoking provides a marker of the biologically effective dose of tobacco carcinogens and assists in individual cancer risk prediction. ${ }^{33}$ 


\section{CONCLUSION:}

Dental professionals areideally placed for early detection of oral lesions associated with tobacco use, not only because the primary focus of the dental examination is intra oral but also because patients are seen on a regular basis. Thus, detection of tobacco-associated lesions needs an adequate knowledge regarding the pathogenesis underlying each lesion. A proper diagnosis of lesion in conjunction with tobacco-use counselling by dental professionals has become the standard of care.

\section{REFERENCES:}

1. Mehta FS, Hamner J E. Tobacco related oral mucosal lesions and conditions in India. A guide for dental students, dentists and physicians. Basic dental research unit. Tata institute of fundamental research.1993, Bombay.

2. Hirsch J M, Heyden G and Thilander H. A clinical, histomorphological and histochemicalstudy on snuffinduced lesions of varying severity. J ournal of Oral Pathology 1982; 11:387-398.

3. Tobacco smoke and invol untary smoking. IARC Monographs on the Evaluation of Carcinogenic Risks to Humans World Health Organization International Agency F or Research On Cancer. Lyon France 2007.

4. J ulia L. Cook. Tobacco Smoke: Chemical Carcinogenesis and Genetic Lesions. The OchsnerJ ournal 1999; 1(3).

5. Oliveira PA, Colaco A, Chaves R, Guedes-Pinto H, Luis F. De-La-Cruz P LF, Lopes C. Chemical carcinogenesis. An Acad Bras Cienc2007; 79(4):593-616.

6. Robbins D and Cotran R. 2005. Pathologic basis of disease. 7th ed., Philadel phia: Elsevier Saunders, p.319-323.

7. Kramer IR, Lucas RB, Pindborg JJ , Sobin LH. Definition of leu-koplakia and related lesions: an aid to studies on oral precancer. Oral Surg Oral Med Oral Pathol 1978; 46:518-539.

8. Axell T, Holmstrup P, Kramer IRH, Pindborg J J, Shear M Inter-national seminar on oral leukoplakia and associated lesions related to tobacco habits. Community Dent Oral Epidemiol 1984; 12:145-154.

9. Grady D. Oral mucosal lesions found in smokeless tobacco users. J Am Dent Assoc 1990; 121:117-123.

10. Chitroda PK, Shah J T, Katti G, Ghali S. Correlative study of smokeless tobacco induced lesion and smoke-induced leukoplakia in various aspects.J I AOMR 2011; 23(2):86-91.

11. Roed-Petersen B. Effect on oral leukoplakia of reducing or ceasing tobacco smoking. ActaDermVener 1982; 62:164-167.

12. Pindborg J J, Reibel J , Roed-Peterson B, Mehta FS: Tobaccoinduced changes in oral leukoplakic epithelium. Cancer 1980; 45:2330-2336.

13. PayneJ B, J ohnson GK, Reinhardt RA, Schmid M. Histological alterations following short-term smokeless tobacco exposure in humans. J Periodont Res 1998; 33:274-279.

14. Murrah V, Gilchrist EP, Moyer MP. Morphologic and growth effects of tobacco-associated chemical carcinogens and smokeless tobacco extracts on human oral epithelial cells in culture. Oral Surg Oral Med Oral Pathol 1993; 75:323332.
15. Thoma KH. Stomatitis nicotine and its effect on the palate Am J Orthod 1941; 27:38-47.

16. Rossie KM, Guggenheimer J . Thermally induced 'nicotine' stomatitis. A case report. Oral Surg Oral Med Oral Pathol 1990; 70(5):597-599.

17. dos Santos RB, Katz J. Nicotinic stomatitis: positive correlation with heat in mate tea drinks and smoking. Quintessence Int 2009; 40(7):537-540.

18. Rajendran R. Benign and malignant tumours of the oral cavity. In: Rajendran R, Shivapathasundaram editors. Shafers textbook of Oral Pathology. $5^{\text {th }}$ ed. New Del hi: Elsevier; 2006:136-139

19. Gupta M.K, Mhaske S, Ragavendra R, Imtiyaz. Oral submucous fibrosis - Current Concepts in Etiopathogenesis. People's J ournal of Scientific Research 2008; 1:39-44.

20. Kumar KK, Saraswathi TR, Ranganathan K, Uma Devi M, Elizabeth J. Oral submucous fibrosis: A clinicohistopathological study in Chennai. Indian J Dent Res 2007; 18(3): 106-111

21. Amarasinghe HK, Usgodaarachchi US, J ohnson NW, Lalloo $\mathrm{R}$, Warnakulasuriya S. Betel-quid chewing with or without tobacco is a major risk factor for oral potentially malignant disorders in Sri Lanka: a case-control study. Oral Oncol 2010; 46(4):297-301.

22. Utsunomiya H, Tilakaratne WM, Oshiro K, Maruyama S, Suzuki $M$, Ida-Yonemochi $M$, et al. Extracellular matrix remodeling in oral submucous fibrosis; its stage-specific modes revealed by immuno-histochemistry and in-situ hybridization. J Oral Pathol Med 2005; 34:498-507.

23. Wang CC, Liu TY, Wey SP, Wang FI, J an TR. Areca nut extract suppresses $\mathrm{T}$-cell activation and interferon- $C$ production via the induction of oxidative stress. Food ChemToxicol 2007; 45:1410-1418.

24. Trivedy C, Warnakulasuriyal KA, Hazarey VK, Tavassoli $M$, Sommer $P$, J ohnson NW. The upregulation of Iysyl oxidase in oral submucous fibrosis and squamous cell carcinoma. J Oral Pathol Med 1999; 28: 246-251.

25. Haque MF, Harris M, Meghji S, Barrett AW I mmunolocalization of cytokines and growth factors in oral submucous fibrosis. Cytokine 1998; 10:713-719.

26. Gupta S, Reddy MV, Harinath BC. Role of oxidative stress and antioxidants in aetiopathogenesis and management of oral submucous fibrosis. Indian J Clin Biochem 2004;19:138-141.

27. J eng J H, Chang MC, Hahn LJ. Role of areca nut in betel quid associated chemical carcinogenesis: Current awareness of future perspective. Oral Oncol 2001; 37:447-492.

28. Carpenter WM. Smoker's melanosis. Emedicine. Dermatology. Diseases of oral mucosa 2009; 6 .

29. Hedin CA. Smoker's melanosis: occurrence and localisation in the attached gingiva. Arch Dermatol 1977; 113:1533-1538.

30. Tobacco smoke and involuntary smoking. Lyon: IARC; 2004. International Agency for Research on Cancer.

31. Hanahan D, Weinberg RA. The hallmarks of cancer. Cell 2000; 100: 57-70.

32. Bartsch H, Rojas $M, N$ air $U$ et al. Genetic cancer susceptibility and DNA adducts: studies in smokers, tobacco chewers, and coke oven workers. Cancer Detect Prev1999; 23:445-453.

33. Hecht SS. Cigarette smoking and lung cancer: chemical mechanisms and approaches to prevention. Lancet Oncol2002; 3:461-469. 